\title{
Using ecologically based relationships to predict distribution of flathead sole Hippoglossoides elassodon in the eastern Bering Sea
}

\author{
Christopher N. Rooper*, Mark Zimmermann, Paul D. Spencer
}

\begin{abstract}
Alaska Fisheries Science Center, National Marine Fisheries Service, 7600 Sand Point Way NE, Seattle, Washington 98115-6349, USA
\end{abstract}

\begin{abstract}
This study describes a method for modeling and predicting, from biological and physical variables, habitat use by a commercially harvested groundfish species. Models for eastern Bering Sea flathead sole Hippoglossoides elassodon were developed from 3 relationships describing the response of organism abundance along a resource continua. The model was parameterized for 1998 to 2000 trawl survey data and tested on 2001 and 2002 data. Catch per unit effort (CPUE) of flathead sole had a curvilinear relationship with depth, peaking at $140 \mathrm{~m}$, a proportional relationship with bottom water temperature, a positive curvilinear relationship with potential cover (invertebrate sheltering organisms such as anemones, corals, sponges, etc.), a negative relationship with increasing mud:sand ratio in the sediment, and an asymptotic relationship with potential prey abundance. The predicted CPUE was highly correlated $\left(\mathrm{r}^{2}=0.63\right)$ to the observations $(1998$ to 2000$)$ and the model accurately predicted CPUE $\left(r^{2}=0.58\right)$ in the test data set $(2001$ and 2002). Because this method of developing habitat-based abundance models is founded on ecological relationships, it should be more robust for predicting fish distributions than statistically based models. Thus, the model can be used to examine the consequences of fishing activity (e.g. reduction in sheltering organisms), changes in temperature (e.g. climate effects) and interaction between variables, and can be modified to incorporate new variables as more information is collected about a species.
\end{abstract}

KEY WORDS: Fish habitat $\cdot$ Habitat model $\cdot$ Bering Sea $\cdot$ Soft sediment $\cdot$ Flatfish

\section{INTRODUCTION}

The multidimensional habitat niche for a given population is defined by its distribution along a combination of multiple resource continua (Hutchinson 1957). For any individual continuum, the relationship between the resource and population abundance can be described by any of a series of increasingly complex equations based on ecological relationships that should determine the population distribution. These include: (1) linear relationships of abundance and resources (Friedlander \& Parrish 1998), (2) a densitydependent response, whereby abundance increases along a resource gradient until intraspecific competition leads to decreasing or stabilized abundance (i.e.
Iles \& Beverton 2000), and (3) an approximate normal or dome-shaped distribution along a resource gradient (May 1973, Murawski \& Finn 1988). In theory, parameterization of the mathematical constructs of these relationships will provide a robust method for predicting population distribution.

In contrast to the ecological relationships mentioned above, the analysis of habitat use of fish populations has largely used statistical models to characterize observed distributions without a priori consideration of ecological theory or mechanisms. These models include simple comparisons of habitat use between areas of high and low density (McConnaughy \& Smith 2000), categorical analysis regression trees (Norcross et al. 1999) and generalized additive models (Swartzman et 
al. 1992, O'Brian \& Rago 1996, Stoner et al. 2001, Simpson \& Walsh 2004, Walsh et al. 2004). General additive models (GAMs) have the advantage of exhibiting nonlinear response curves describing the relationship between fish distributions and habitat, but the shape of the response curves may be difficult to explain in terms of organism ecology. It is notable that existing statistical habitat models are rarely used for prediction (but see Stoner et al. 2001 for exception), because the statistical relationships describing existing distributions may not be applicable to future distributions (Beutel et al. 1999). Utilization of ecological relationships provides the advantages of nonlinearity in modeling distributions across habitats, a distribution response for each habitat variable that is justifiable based on organism ecology, and therefore a more robust prediction of future organism distribution across habitats than traditional statistical models.

The characterization of habitat use is also dependent on the habitat variables used in the analysis. For example, Swartzman et al. (1992) modeled 5 eastern Bering Sea flatfish species (rock sole Lepidopsetta sp., Alaska plaice Pleuronectes quadrituberculatus, flathead sole Hippoglossoides elassodon, yellowfin sole Pleuronectes asper and Greenland turbot Reinhardtius hippoglossoides) using a GAM with temperature and depth as predictor variables, and concluded that depth is the primary factor influencing flatfish distributions. However, McConnaughy \& Smith (2000) noted that sediment characteristics differed between areas of high and low flatfish abundance and proposed that differences in the availability and quality of prey may explain sediment preferences among the same 5 species of flatfish and arrowtooth flounder Atheresthes stomais. Incorporating a full suite of habitat variables into the analyses is important for determining the factors that determine fish distribution.

The primary objective of this study was to develop and demonstrate a method of predicting fish distribution and abundance across multiple resource continua based on the ecological relationships described above. We used log-likelihood methods to fit ecologicallybased models to catch data, utilizing multiple habitat variables including potential prey, potential cover, temperature, sediment type and depth. Flathead sole in the eastern Bering Sea was chosen as the species to illustrate this method because (1) an annual fisheryindependent trawl survey documents flathead sole distribution, abundance and related habitat data, (2) the survey samples the depth and temperature range of flathead sole, and (3) flathead sole abundances vary across the geographic range of the survey. Flathead sole are distributed throughout the North Pacific Ocean from Monterey, California, to the Chukchi Sea (Kramer et al. 1995), and are a component of Bering
Sea commercial bottom-trawl fisheries, with annual catches averaging 18000 t since 1990 (North Pacific Fishery Management Council 2003). Flathead sole spawning occurs in the spring, as eggs are present in April to early July over the outer domain (>100 m depth) of the eastern Bering Sea shelf (Grigorev \& Fadeev 1995). As with many flatfish species, the buoyant eggs and larvae are transported to nursery grounds in shallow inshore areas (Alderdice \& Forrester 1974, Haldorson et al. 1993, Abookire \& Norcross 1998). Juvenile flathead sole exhibit strong preferences for specific depth and sediment ranges in coastal embayments in the Gulf of Alaska (Abookire \& Norcross 1998), but the distribution of adult and subadult flathead sole relative to habitat features are for the most part unknown, particularly in the Bering Sea. Our hypothesis was that flathead sole catches across the Bering Sea shelf would be related to food availability, temperature, depth, sediment type and shelter available. Modeling was conducted on 4 groups of the catch data (all flathead sole combined, subadults, mature females and mature males) over 3 yr of Bering Sea trawl surveys. The best-fitting model was then tested on data collected during the subsequent 2 surveys.

\section{MATERIALS AND METHODS}

Collection. Data for this study were collected during annual trawl surveys conducted by the National Marine Fisheries Service (NMFS) from 1998 to 2002 during the summer months (Acuna et al. 2003). Stations for the trawl survey are evenly distributed over a 20 nautical mile grid system on the eastern Bering Sea shelf, except in 2 areas where additional stations have been placed within the grid system (Fig. 1). An 83-112 eastern otter trawl equipped with net mensuration gear, bottom contact sensor and temperature-depth recorder (SeaBird SBE 39) was towed for $30 \mathrm{~min}$ on the seafloor through the middle of each grid cell (see Acuna et al. 2003 for detailed description of the Bering Sea trawl survey methods, gear and data). Depths of the survey ranged from $16 \mathrm{~m}$ near Nunivak Island to $>180 \mathrm{~m}$ along the Bering Sea shelf edge. Only tows with good performance and suitable bottom contact (Gary Walters, NOAA NMFS RACE, pers. comm.) were used in the analysis. The number of good-performance tows ranged from 349 in 1999 to 355 in 2001. Tows with a recorded catch of flathead sole, but with no size information were discarded, resulting in a total of 1758 useable tows over $5 \mathrm{yr}$ (Table 1).

Adult flathead sole were divided into 2 groups based on their total body length taken from each haul: 


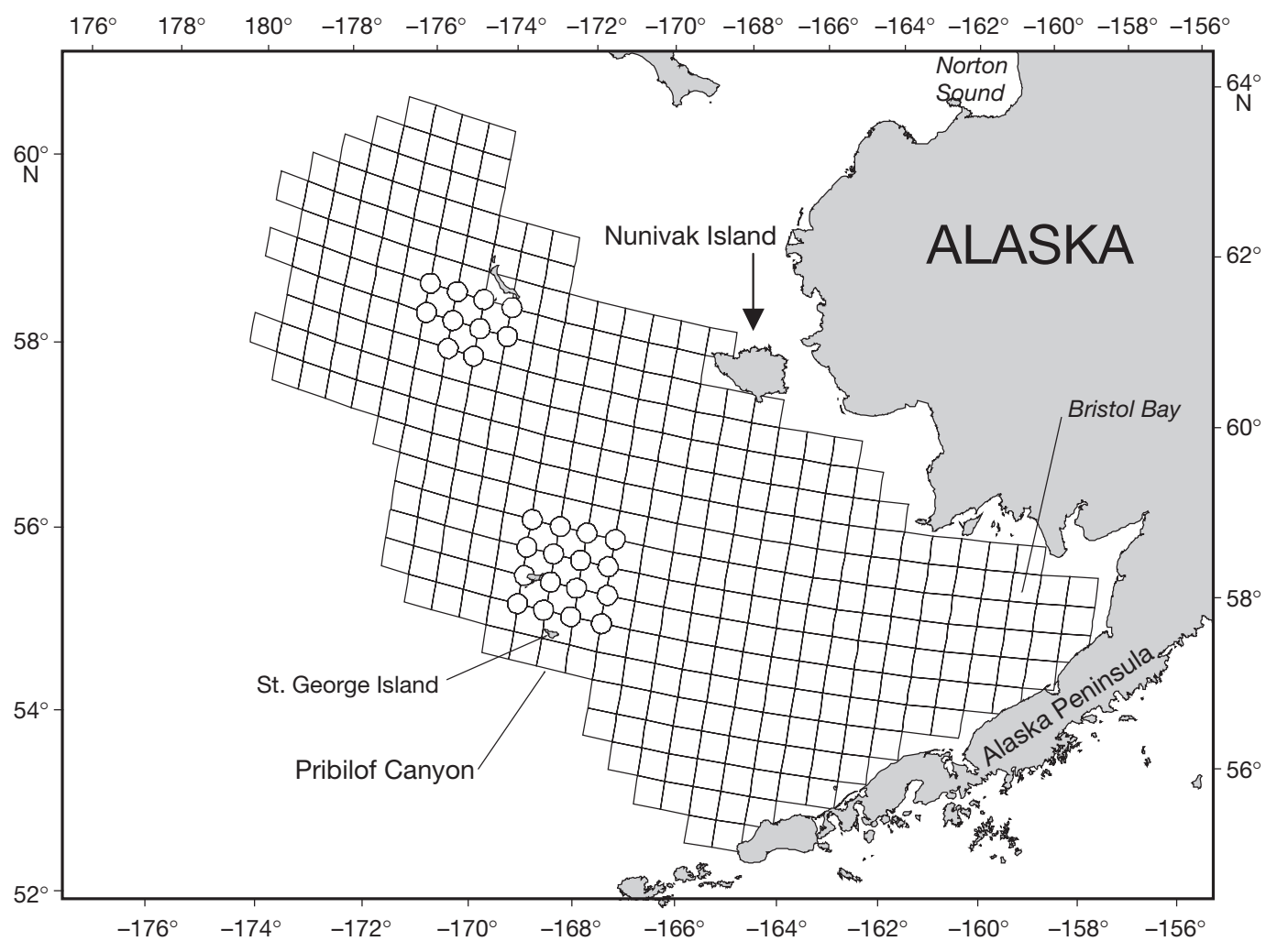

Fig. 1. Map of the Bering Sea showing 20 nautical mile grid of survey stations. In each summer from 1998 to 2002 , 1 survey trawl was conducted near the center of each box of the grid; 1 survey trawl was also conducted using same method near the center of each circle in each summer

subadults and mature adults. The mature adults were further divided into males and females. Juvenile fish $<150 \mathrm{~mm}$ in total length (TL) (Holladay \& Norcross 1995, Abookire et al. 2001) were not included in the analysis because they were rarely caught by the research trawl and were assumed to have different distributions based on previous research (Norcross et al. 1997, Abookire \& Norcross 1998). Subadult fish were defined as those $<300 \mathrm{~mm}$ in TL (younger than $9.7 \mathrm{yr}$ ), the estimated age and size of $50 \%$ maturity (Stark 2004), and $>150 \mathrm{~mm}$ TL (older than age $1+\mathrm{yr}$ ). Subadults included males and females combined in a single group, but adult fish (>300 mm TL) were divided into male and female segments. Catch per unit effort (CPUE) was estimated for each group as no. captured $\mathrm{ha}^{-1}$ swept by the net during each tow in the NMFS trawl survey.

Habitat variables. Habitat variables were chosen based on their hypothesized importance for growth, survival and regulation of metabolism. The suite of variables included depth, temperature, potential cover, sediment type (defined as mud:sand ratio) and potential prey. Bottom temperature and depth were averaged during the period of bottom contact of each trawl haul. For tows with no associated temperature data, a temperature value was linearly interpolated from the closest adjacent stations in the survey grid sampled on the same day.

In this analysis, potential cover was defined as epibenthic organisms and associated organic material that extend above the sea bottom. Taxa included soft and hard corals, surface bivalves and empty bivalve shells, ascidians, gastropods, sponges, anemones, bryozoans and sea pens. Potential cover was estimated as the combined catch per unit effort of sheltering organ-

Table 1. Hippoglossoides elassodon. Mean CPUE and standard error (SE), for adult flathead sole, and number of trawl survey stations occupied each year for modeled data (1998 to 2000) and test data (2001 and 2002)

\begin{tabular}{|c|c|c|c|}
\hline \multirow[t]{2}{*}{ Year } & \multicolumn{2}{|c|}{ CPUE (no. ha-1) } & \multirow[t]{2}{*}{$\mathrm{n}$} \\
\hline & Mean & SE & \\
\hline 1998 & 38.05 & 5.69 & 350 \\
\hline 1999 & 22.72 & 2.23 & 349 \\
\hline 2000 & 23.36 & 2.31 & 351 \\
\hline 2001 & 32.08 & 3.45 & 355 \\
\hline 2002 & 30.02 & 4.01 & 353 \\
\hline
\end{tabular}


isms recovered from each trawl $\left(\mathrm{kg} \mathrm{ha}^{-1}\right)$, and used as an index of available epibenthic shelter.

Sediment type data were derived from Smith \& McConnaughey (1999), and were assumed to be constant over the years. Sediment characteristics in the Bering Sea from a number of studies have been compiled into a database containing 2587 observations (Smith \& McConnaughey 1999). Because the point locations of the sediment size data do not correspond to the survey stations, the predicted mud.sand ratio at the survey stations was obtained from ordinary kriging (Isaaks \& Srivastava 1989). The sand classification encompassed sediment ranging from very fine to very coarse sand $(-1<\phi<4)$, while the mud classification encompassed sediment from clay to coarse silt $(\phi>4)$ (Wentworth 1922). Larger-grained sediments (gravel) occurred in significant quantities ( $>10 \%$ by weight) at only 20 of the 358 trawl stations, and thus gravel was not included in the definition of sediment type. To satisfy the stationarity assumption, an overall trend from low mud:sand ratios in the central shelf to high ratios in the northwest shelf was removed with a local regression scatterplot smoother, and kriging was conducted on the residuals from this trend. This trend can be explained by stronger wave energy in nearshore, shallow locations being sufficient to suspend smaller particles, with sediment size generally decreasing with increasing distance from shore. Areas of medium and fine silt occur in the southwestern and northwestern shelf, respectively. A spherical variogram model was fit to data with a maximum distance of $250 \mathrm{~km}$ and checked for isotropy. The predictions from the krigged surface were then added to the underlying trend to obtain predicted values of the mud:sand ratio at each trawl survey station.

Flathead sole prey on mysids, euphausids, decapods (including shrimp and pagurid crabs), juvenile walleye pollock ( $<200 \mathrm{~mm}$ TL) and, especially, ophiurids (Pacunski et al. 1998). All these groups are epibenthic species, and all except mysids and euphausids are commonly captured in trawl surveys. Mysids and euphausids comprise $<6 \%$ of the flathead sole diet measured by weight (Pacunski et al. 1998), and were considered a minor diet component. The total catch per unit effort $\left(\mathrm{kg} \mathrm{ha}^{-1}\right)$ of those prey items captured in the trawl survey was summed for each station as an index of potential prey. In some trawls $(\mathrm{n}=8)$, walleye pollock were not measured for total length. In these cases the average individual weight (total catch weight/total catch numbers) was calculated. If the average individual weight was less than $0.5 \mathrm{~kg}$, the catch was assumed to be composed of entirely juvenile fish; if the average weight was greater than $0.5 \mathrm{~kg}$, the entire catch was assumed to be adults.
Model structure. Prior to fitting the parameters for each model, CPUE data were log +1 transformed, so in the following equations CPUE refers to the logtransformed data. A model of flathead sole CPUE was estimated, whereby CPUE is a function $(f)$ of the 5 habitat variables depth $(D)$, temperature $(T)$, potential cover $(C)$, mud:sand ratio $(M)$, potential prey $(P)$ and an error term $(\varepsilon)$ :

$$
\text { CPUE }=f(D)+f(T)+f(C)+f(M)+f(P)+\varepsilon
$$

The relationships between flathead sole CPUE and habitat variables were estimated using one of 3 equations. The most complex equation had 3 parameters, and represented the response of CPUE as a domeshaped function of the habitat variables, so that:

$$
\mathrm{CPUE}_{h}=\alpha_{h}+\beta_{h} X_{h}+\delta_{h} X_{h}^{2}
$$

Here, $X_{h}$ is habitat variable $h$, while $\beta_{h}, \delta_{h}$ and $\alpha_{h}$ are parameters fitted to the data. The second equation describes CPUE as a density-dependent function of the habitat variables, so that:

$$
\mathrm{CPUE}_{h}=a_{h} X_{h} \mathrm{e}^{-b_{h} X_{h}}
$$

In this case, $a_{h}$ and $b_{h}$ are the parameters fit. The simplest equation utilized predicted flathead sole density as proportional to the habitat variables $X_{h}$, so that:

$$
\mathrm{CPUE}_{h}=a_{h} X_{h}
$$

where $a_{h}$ is the only parameter fit in the equation.

All components of CPUE were combined prior to fitting the parameters. For example, the initial (full) model for the analyses estimated 15 parameters and included depth (Eq. 2), temperature (Eq. 2), mud:sand ratio (Eq. 2), potential cover (Eq. 2) and potential prey (Eq. 2), so that:

$$
\begin{aligned}
\mathrm{CPUE}= & \alpha_{D}+\beta_{D} X_{D}+\delta_{D} X_{D}^{2}+\alpha_{T}+\beta_{T} X_{T}+\delta_{T} X_{D}^{2}+ \\
& \alpha_{C}+\beta_{C} X_{C}+\delta_{C} X_{C}^{2}+\alpha_{M}+\beta_{M} X_{M}+\delta_{M} X_{M}^{2}+ \\
& \alpha_{P}+\beta_{P} X_{P}+\delta_{P} X_{P}^{2}+\varepsilon
\end{aligned}
$$

All 15 parameters for the suite of habitat variables were fit simultaneously.

The errors, $\varepsilon$, were then assumed to be distributed log-normally, and modeling parameters were estimated by minimizing the negative log-likelihood (Hilborn \& Mangel 1997):

$$
-\ln (L)=\sum\left[\log (\sigma)+\frac{1}{2} \log (2 \pi)+\frac{(Y-\hat{Y})^{2}}{2 \sigma^{2}}\right]
$$

where $\sigma$ is estimated analytically by:

$$
\sigma=\sqrt{\frac{\sum(Y-\hat{Y})^{2}}{n-1}}
$$

$L$ is the likelihood, $Y$ are the observed CPUE data and $\hat{Y}$ are the predicted values. 
Models were reduced by sequentially removing 1 parameter for each variable (i.e. the depth relationship was changed from Eqs. 2 to 3), and parameters were refit. The models were compared using the Akaike information criterion (AIC) for non-nested models to determine the best-fitting model:

$$
\mathrm{AIC}=L+2 \mathrm{P}
$$

where $\mathrm{P}$ is the number of parameters in Model $M$ (Akaike 1992). The best 14-parameter model was then evaluated against the full 15-parameter model. Next, the process was repeated, eliminating another parameter and testing the resulting 13-parameter models to the best 14-parameter model. This process was repeated until reduction in the number of parameters resulted in no reduction in AIC score, and this final model was deemed best for the data set analyzed. The correlation between the observed and predicted values was used to determine the percentage of variance in the CPUE data set explained by the model. Deviations (observed values minus predicted values) for the model were explored through examination of residuals via a geographic information system (GIS) to examine spatial patterns.

Model cross-validation. Once a final model was determined for the 1998 to 2000 trawl survey data, the model was tested on flathead sole catch data from the Bering Sea trawl surveys of 2001 and 2002. The 2001 and 2002 catch data, depth, temperature, potential cover, mud:sand ratio and potential prey for each station were compiled into a matrix. The parameters from the best-fitting model for 1998 to 2000 were used to predict the 2001 and 2002 flathead sole distribution. The error of the model for 2001 and 2002 data was calculated as the observed CPUE minus the CPUE predicted using the 1998 to 2000 model and parameters, and the percentage of explained variance in the 2001 and 2002 CPUE data was estimated.

\section{RESULTS}

Catch of flathead sole ranged from 0 to 4694 individuals in 1998 to 2000 , with $20 \%$ of the trawl hauls capturing zero flathead sole. The catch was evenly divided between mature adults (53\%) and subadults (47\%), and the mature adults were composed of $46 \%$ females and $54 \%$ males. Trawl survey data were collected at depths ranging from 16 to $188 \mathrm{~m}$, with stations fairly evenly distributed at depths between 35 and $135 \mathrm{~m}$ (Fig. 2). Bottom water temperatures during the 1998 to 2000 trawl surveys ranged from -1.7 to $6.6^{\circ} \mathrm{C}$ and most temperatures were between 0 and $4^{\circ} \mathrm{C}$ (Fig. 2). The catch of potential cover ranged from 0 to $1366 \mathrm{~kg} \mathrm{ha}^{-1}$, and at most sites the CPUE of invertebrates was less
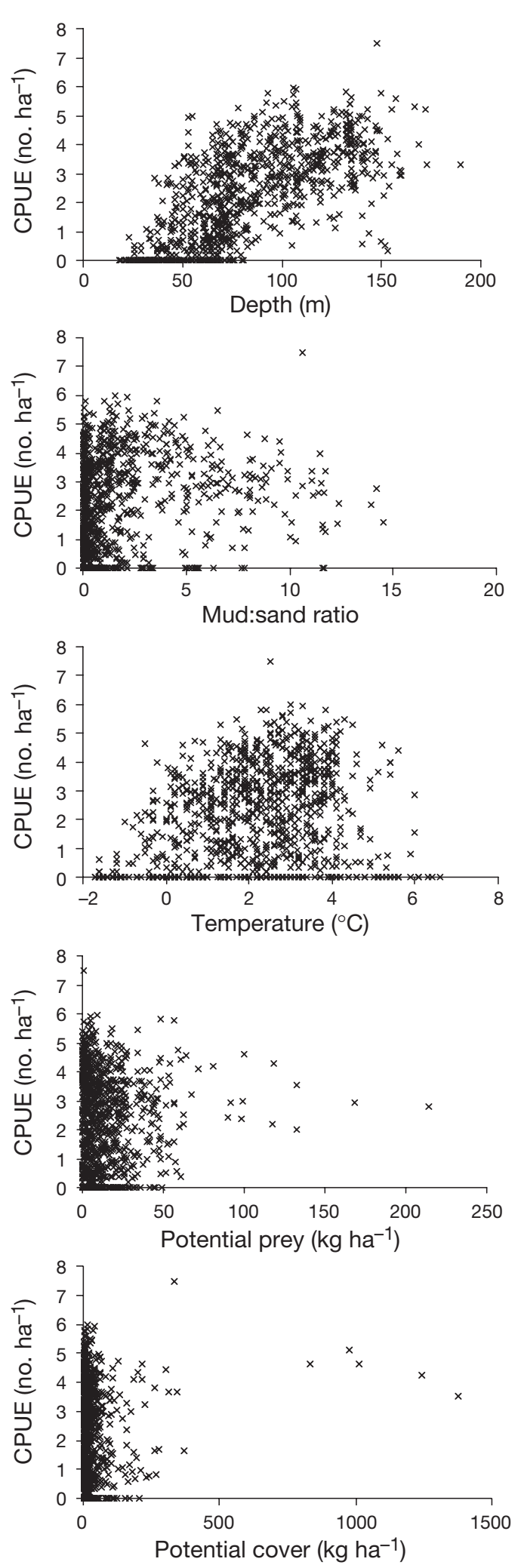

Fig. 2. Hippoglossoides elassodon. Distributions of flathead sole catch per unit effort (CPUE) across habitat variables for 1998 to 2000 trawl survey data. Mud:sand ratio predicted from krieged data (Smith \& McConnaughey 1999); other habitat data collected on 1050 trawl survey tows 

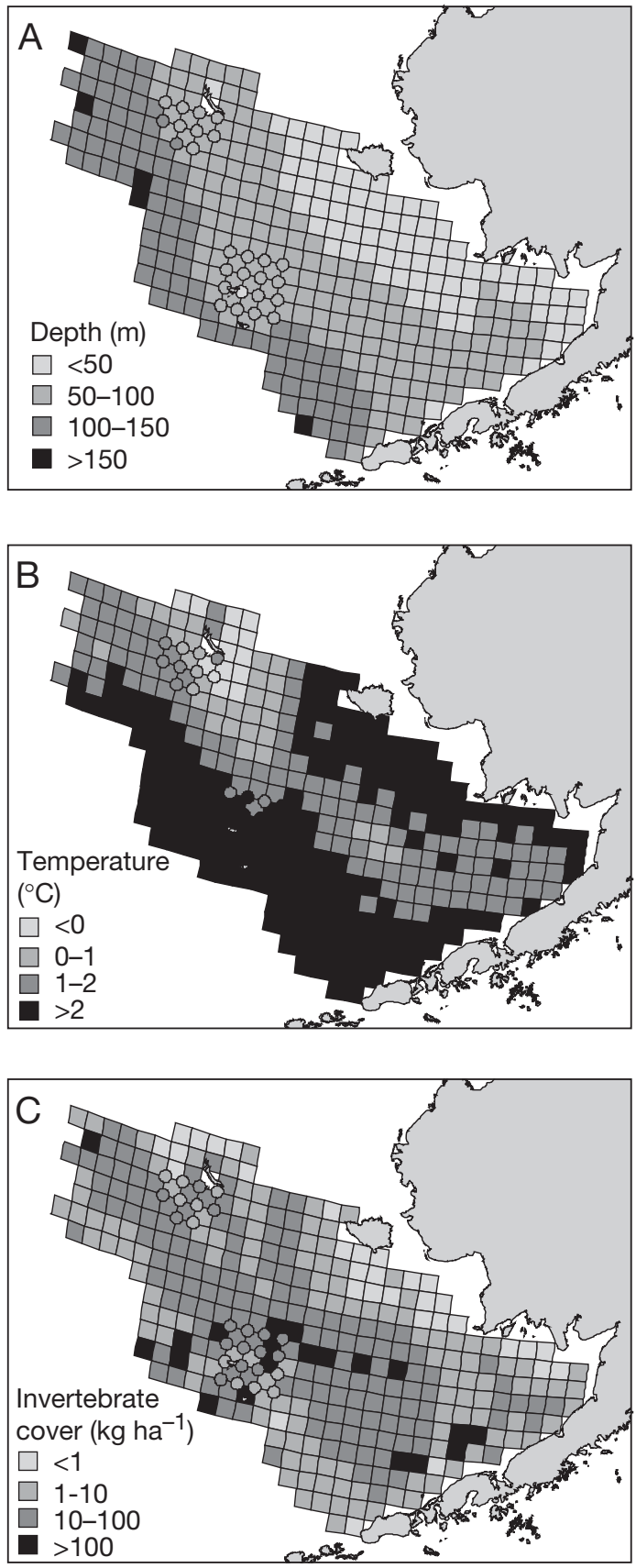

than $45 \mathrm{~kg} \mathrm{ha}^{-1}$ (Fig. 2). The mud:sand ratio ranged from 0 to 14 (Fig. 2). Over $50 \%$ of the sites had sediment samples composed of mostly sand-sized particles, and thus mud:sand ratios of $<1$. Total potential prey ranged from 0 to $214 \mathrm{~kg} \mathrm{ha}^{-1}$, with the majority of sites having less than $20 \mathrm{~kg} \mathrm{ha}^{-1}$ of flathead sole diet components. The mid-shelf region (depths between 50 and $100 \mathrm{~m}$ ) was dominated by temperatures from -1 to $2{ }^{\circ} \mathrm{C}$, had variable mud:sand ratios and was interspersed with large volumes of potential cover (Fig. 3). High catches of flathead sole prey items were distributed
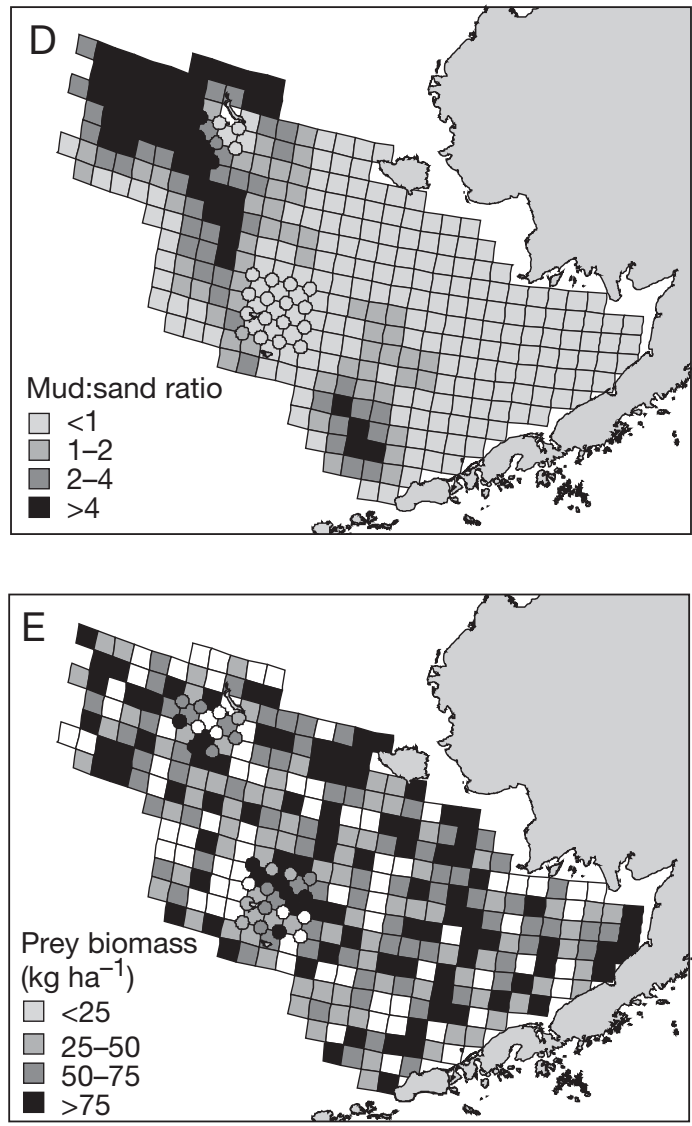

Fig. 3. Average distributions of habitat variables from trawl survey data (1998 to 2000 surveys) and mud:sand ratios krieged from sediment database. White squares in panel E: no prey items captured during surveys

across the entire shelf, with no apparent pattern. Muddominated stations were mostly in the northern outershelf region (Fig. 3).

The best model of flathead sole (combined subadults and adults from 1998 to 2000) habitat-use included all 5 habitat variables; depth, temperature, potential cover, mud:sand ratio and potential prey (Table 2). This model was reduced from the original 15-parameter model to a 10-parameter model. The 10parameter model predictions were highly correlated $\left(\mathrm{r}^{2}=0.63\right)$ to the observations, and the majority of 
Table 2. Hippoglossoides elassodon. Best-fitting models for flathead sole habitat use. For each group of flathead sole (by maturity and by sex) the full model was the 15-parameter model of Eq. (5); for each habitat variable, the number of parameters and equation are shown in body of table (see 'Materials and methods' for definitions). Number of parameters (P) for each model, Akaike information criterion (AIC) for full and reduced models, and $r^{2}$ value for observed versus predicted values are given. -: variable not included in model

\begin{tabular}{|lcccccrrr|}
\hline Data set & Depth & $T$ & $\begin{array}{c}\text { Potential } \\
\text { cover }\end{array}$ & $\begin{array}{c}\text { Mud:sand } \\
\text { ratio }\end{array}$ & $\begin{array}{c}\text { Potential } \\
\text { prey }\end{array}$ & P & \multicolumn{2}{c|}{$\begin{array}{c}\text { AIC model } \\
\text { Feduced }\end{array}$} \\
\hline Combined & 2 (Eq. 3) & 1 (Eq. 4) & 3 (Eq. 2) & 2 (Eq. 3) & 2 (Eq. 3) & 10 & 1552 & 1524 \\
Mature females & 2 (Eq. 3) & 2 (Eq. 3) & - & 2 (Eq. 3) & - & 6 & 1422 & 1404 \\
Mature males & 3 (Eq. 2) & 2 (Eq. 3) & 3 (Eq. 2) & 1 (Eq. 4) & - & 9 & 1411 & 1399 \\
Subadults & 3 (Eq. 2) & 1 (Eq. 4) & 3 (Eq. 2) & 3 (Eq. 2) & 2 (Eq. 3) & 12 & 1465 & 1457 \\
\hline
\end{tabular}

predictions $(67 \%)$ fell within 1.0 of the observed CPUE, which is approximately $50 \%$ of the overall mean CPUE $=2.12$ (Fig. 4). The model included depth as a 2-parameter model (Eq. 3), whereby flathead sole CPUE decreased at depths of $<140 \mathrm{~m}$ (Fig. 5). The model predicted a linear relationship between CPUE and temperature with a slope of 0.29 (Eq. 4, Fig. 5). The relationship between potential cover followed Eq. (2), with an exponential increase in flathead sole CPUE with increasing potential cover (Fig. 5). Flathead sole CPUE decreased sharply at mud:sand ratios $>0.1$ (Eq. 3, Fig. 6). Flathead sole CPUE increased to an asymptote at potential prey $>30 \mathrm{~kg} \mathrm{ha}^{-1}$ (Fig. 5).

Modeling was also carried out on subadult fish and the 2 sexes of mature adults separately, for a total of 3

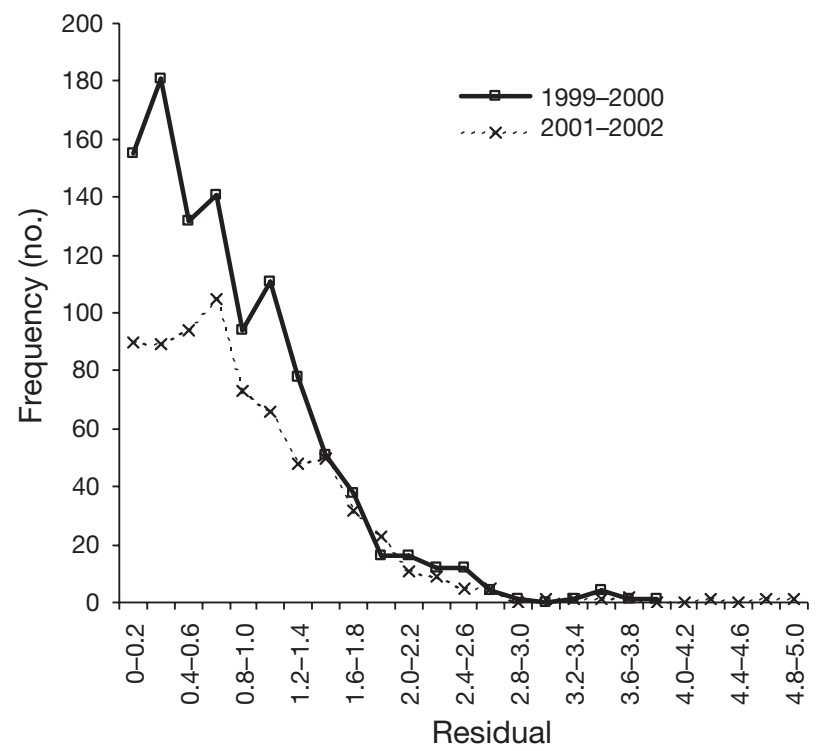

Fig. 4. Hippoglossoides elassodon. Frequency (no.) histogram of absolute values of residuals from observed and predicted CPUE. For 1998 to 2000 , predicted data generated from bestfitting model of flathead sole habitat use $(n=1050)$; for 2001 and 2002, predicted data generated from best-fitting model of flathead sole habitat-use developed from analysis of 1998 to 2000 data $(\mathrm{n}=708)$ more modeling analyses. The best-fitting model for mature females explained only $41 \%$ of the variance in the CPUE data, and contained the depth, temperature and mud:sand ratio variables (Table 2). The major differences between the female and combined flathead sole model was that the female-temperature relationship followed Eq. (3), while the potential cover and potential prey variables were dropped from the analysis. The best-fitting model of male habitat association also explained $41 \%$ of the variance in the data set (Table 2), and was the similar to the model for combined adult flathead sole. The major difference between the combined and male flathead models was the elimination of the potential prey variable from the latter analysis. When subadults were modeled, the best-fitting model was similar to the model of all flathead sole, but did not explain as much of the variance in the data set (Table 2). The only differences between the subadult model and the combined flathead sole model were in the depth and mud:sand ratio variables. The model of all flathead sole combined fitted the data much better than any of the individual models divided by maturity and sex, and was thus chosen as the best model for examination of the test data.

The best-fitting model equations and parameters developed for the 1998 to 2000 data (Fig. 5) were utilized to test the model on the 2001 and 2002 trawl survey data. The majority of individual predictions (64\%) fell within 1.0 of the observed CPUE, which was again $<50 \%$ of the overall mean CPUE $=2.16$ (Fig. 4). The fit of the model to the test data was almost as good as the original fit on the 1998 to 2000 data (Fig. 6), as the predicted values were also highly correlated $\left(r^{2}=0.58\right)$ to the observations. The model fit was adequate for the majority of the CPUE observations from 1 to 5 , but the model had difficulty predicting the largest observations of flathead sole CPUE, as well as trawl hauls where zero flathead sole were captured.

Spatial plots of model residuals indicate that the model tended to under-predict (positive residuals) observed CPUE in the southern region of the Bering 

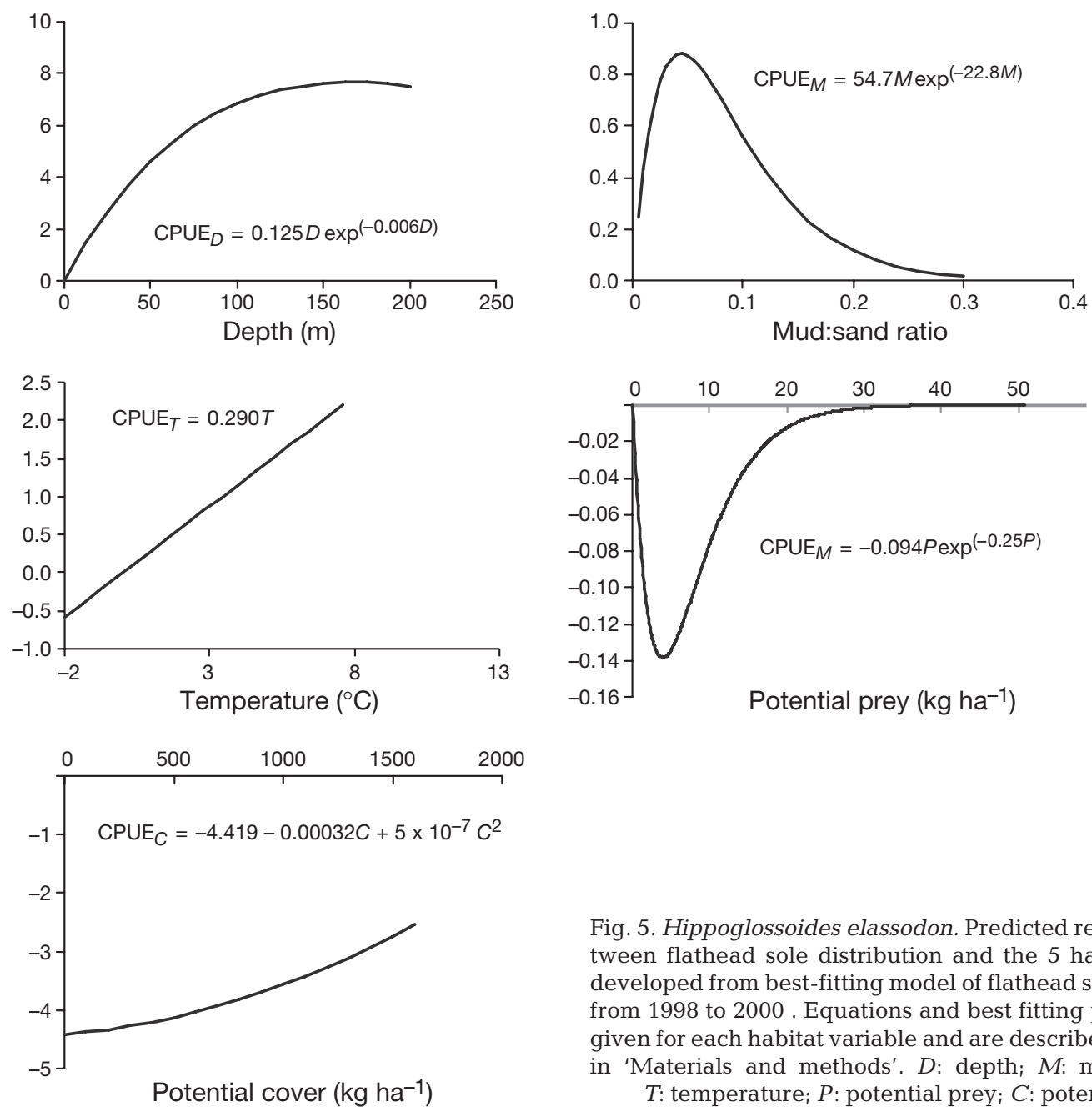

Fig. 5. Hippoglossoides elassodon. Predicted relationships between flathead sole distribution and the 5 habitat variables developed from best-fitting model of flathead sole distribution from 1998 to 2000 . Equations and best fitting parameters are given for each habitat variable and are described in Eqs. 2 to 4 in 'Materials and methods'. $D$ : depth; $M$ : mud:sand ratio;

$T$ : temperature; $P$ : potential prey; $C$ : potential cover

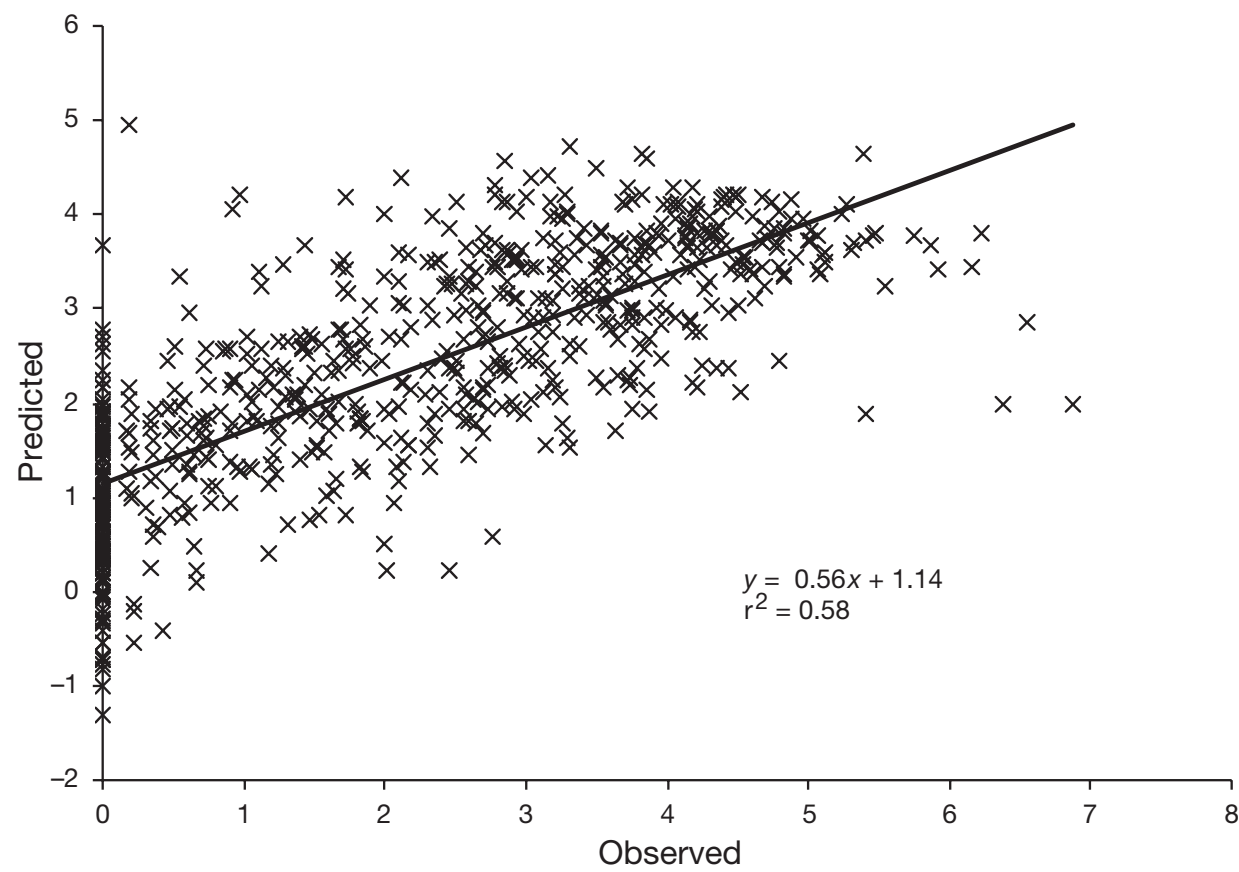

Fig. 6. Hippoglossoides elassodon. Predicted and observed CPUE values for test data set of the Bering Sea flathead sole for 2001 and 2002. Predicted data generated from bestfitting model of flathead sole habitat-use developed from analysis of 1998 to 2000 data 

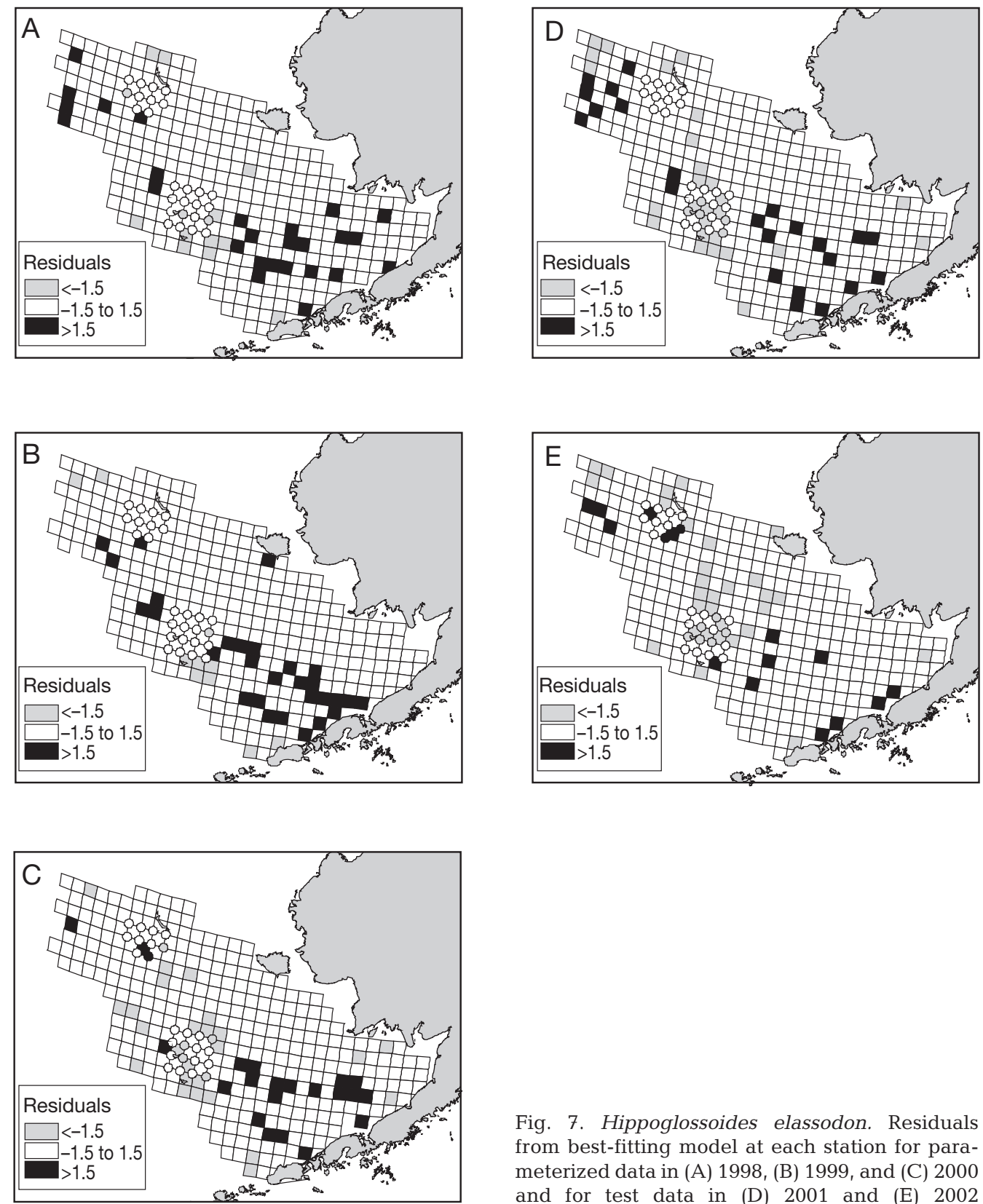

Fig. 7. Hippoglossoides elassodon. Residuals from best-fitting model at each station for parameterized data in (A) 1998, (B) 1999, and (C) 2000 and for test data in (D) 2001 and (E) 2002

\section{DISCUSSION}

observed CPUE in the central shelf (Fig. 7). In 2001 and 2002, positive and negative residuals were more evenly distributed across the shelf. The largest positive deviations from the observed data occurred near the northern Aleutian chain and Bristol Bay in all years. The largest negative deviations occurred most consistently around the edge of Pribilof canyon, south of St. George Island, although large negative deviations also occurred through the middle of the Bering Sea shelf (Fig. 7). 
the Bering Sea shelf (Schumacher \& Kinder 1983). This area of the shelf is typically dominated by the degree of ice cover over the winter and spring (Wyllie-Echeverria \& Ohtani 1999). Production is controlled by spring water-column stability determined by the timing and location of ice retreat (Niebauer et al. 1981). In years of strong ice cover, a pool of water colder than $2^{\circ} \mathrm{C}$ forms in summer on the middle and outer shelf (WyllieEcheverria \& Ohtani 1999) and can persist throughout the summer. Previous investigations of flathead sole distribution on the Bering Sea shelf indicated that water temperatures below $2^{\circ} \mathrm{C}$ and higher than $4.3^{\circ} \mathrm{C}$ were avoided by flathead sole (Mineva 1964). Additionally, studies of energy requirements have found high $Q_{10}$ values for flathead sole, indicating a relatively narrow thermal range (Paul et al. 1995). Our analysis is consistent with the lower temperature boundary, as modeling indicated a steep decline in flathead CPUE below $2{ }^{\circ} \mathrm{C}$, and suggests that flathead sole avoid the pool of colder water on the mid-shelf. In this analysis, however, the model did not predict any decline in CPUE at higher temperatures. The lack of a declining CPUE trend at higher temperatures may be an artifact of the small number of trawl survey collections at temperatures greater than $4^{\circ} \mathrm{C}$.

Sediment characteristics have often been found to influence the distribution of flatfishes. In this study, sediment type (as represented by the mud:sand ratio) exhibited a strong relationship with the summer distribution of flathead sole. Flathead sole CPUE increased sharply as the mud:sand ratio increased, and then the effect of sediment on CPUE declined to near zero at mud:sand ratios $>0.3$. A previous analysis of flathead sole distribution in the Bering Sea using the same sediment data (but an earlier period of trawl survey data) indicated that this species preferred areas of mixed sand and mud, where its primary prey item (ophiuriods) was present in high densities (McConnaughey \& Smith 2000). The diet data presented by McConnaughey \& Smith (2000) suggest that flathead sole are generalist feeders, consuming walleye pollock when occupying sandy areas and ophiuriods when occupying mixed mud and sand areas. In this study, increases in potential prey resulted in increased flathead sole CPUE, while the effect of sediment type was only important to the flathead sole catch over a small range of values, consistent with the dietary explanation for sediment preference proposed by McConnaughey \& Smith (2000).

Other studies of flatfish distribution have found that the presence of structure can increase the density of individuals. Sheltering structure such as benthic invertebrates, overlying litter, etc. are associated with increased abundance of juvenile flatfish in nursery areas (Howell et al. 1999, Stoner \& Titgen 2003), and presumably enhance survival through mitigation of predation (Orth et al. 1984, Fernandez et al. 1993, Laurel et al. 2003, Stoner \& Titgen 2003) or collection of prey in areas of complex benthic structure (Stevens \& Anderson 2000). In the current study, the presence of invertebrate sheltering organisms in the trawl survey was predicted to increase the abundance of flathead sole in the catch. There was no available information from the Bering Sea trawl surveys to identify other types of structure, such as sand waves, that could alternatively provide shelter for flathead sole. Western Bristol Bay, where unusual bed forms (sand waves, faults and seafloor depressions) have been mapped using sidescan sonar (Schwab \& Molnia 1987, Marlow et al. 1999), was a location where the model predicted lower values than were observed. Sand waves have also been observed at other locations in the Bering Sea outside the region included in the trawl survey (Field et al. 1981, Hunter et al. 1982). Therefore, the trawl survey catch of potential cover does not account for all types of shelter available to demersal fishes.

Correlations among the initial group of habitat variables made it difficult to partition the amount of flathead sole CPUE accounted for by individual variables (Table 3). Most of these relationships were weakly significant $(\mathrm{r}<0.10)$ with the exception of the sediment-depth (0.44) and sediment-temperature (0.25) correlations. Independence among the 5 variables was not a necessary assumption of this modeling effort; however, it does complicate the interpretation of the results. For example, some variability in the catch that was attributed to depth in the model may have actually been a function of changes in sediment type, as sampling moved deeper. However, removal of either depth or sediment type from the analysis resulted in a significantly weaker fit to the data.

The basin theory predicts that the distribution of a fish species should expand during periods of high population abundance and contract during periods of low abundance (MacCall 1990), a phenomenon for which some evidence exists in flathead sole (McConnaughey 1995). If flathead sole distribution responds to overall abundance patterns in the Bering Sea, it would be

Table 3. Correlations (r values) among habitat variables in 1998 to 2000 Bering Sea survey data. ${ }^{*}$ : linear regression of variables was significant at $\mathrm{p}<0.05$

\begin{tabular}{|lccccc|}
\hline Parameter & Depth & $\begin{array}{c}\text { Tem- } \\
\text { perature }\end{array}$ & $\begin{array}{c}\text { Potential } \\
\text { cover }\end{array}$ & $\begin{array}{c}\text { Mud:sand } \\
\text { ratio }\end{array}$ & $\begin{array}{c}\text { Potential } \\
\text { prey }\end{array}$ \\
\hline Depth & 1 & & & & \\
Temperature & $0.07^{*}$ & 1 & & & \\
Potential cover & 0.02 & 0.02 & 1 & & \\
Mud:sand ratio & $0.44^{*}$ & $0.25^{*}$ & $0.09^{*}$ & 1 & 1 \\
Potential prey & 0.05 & 0.05 & $0.09^{*}$ & $0.06^{*}$ & 1 \\
\hline
\end{tabular}


expected that the parameters of habitat relationships would change in concurrence with changes in abundance. For example, the most dramatic cold pool extension over the shelf during the period examined in this study occurred in 1999, when cool water was recorded throughout the middle domain and most of the outer domain above the Pribilof Islands. This should have resulted in cold pool avoidance by flathead sole and either higher catches over the outer shelf due to crowding of the population or higher catches in areas not typically utilized by flathead sole due to dispersal away from colder water. The residuals of the model fit in 1999 under-predict catches on the southern half of the Bering Shelf, especially inside the $100 \mathrm{~m}$ isobath (Fig. 7B), suggesting that the extensive cold pool in 1999 may have changed the distribution of flathead sole across the shelf.

Although this modeling approach was effective for predicting over half the variation in flathead sole CPUE, there was still considerable unexplained variability. The model fit could probably be improved by including more accurate measures of the variables that were indices of available resources. Sampling biases due to inaccurate measurement of important variables such as potential prey and potential cover are a problem in the analysis, and because we utilized only 1 sampling method (bottom trawl) probably contributed to the unexplained variance in the model. Another potential source of unexplained variation in the results could be variables that were missed by this study, such as competition with other species of fishes and invertebrates. The broad scale of this study (encompassing the entire Bering Sea shelf) would benefit from smallerscale information that could more clearly develop mechanistic relationships between CPUE and habitat variables while controlling for confounding factors.

The modeling method demonstrated here is important in advancing fisheries science because predictive models can be utilized to forecast the effects of fishing activity and climate change on a population. One of the advantages of this modeling study over non-predictive models is that the relationship between flathead sole CPUE and the various habitat variables can be explored simultaneously. This is especially valuable in developing methods for ecosystem-based management and for describing essential fish habitats. Currently, there is an emerging discussion of the effects of fishing on essential habitats for fish species. Sheltering invertebrates are susceptible to trawling activity (McConnaughey et al. 2000, Freese 2001, Wassenberg et al. 2002), and were found to be important to flathead sole distribution in the current study. If the relationship between flathead sole and potential cover estimated in the current modeling analysis is robust, the effect of substrate removal on flathead sole distribution can be easily predicted. For example, if there is an $80 \%$ reduction in the catch of invertebrates across the Bering Sea shelf, a reduction in flathead sole CPUE of $<1 \%$ would be expected. Interestingly, a drop in temperature across the shelf of $1^{\circ} \mathrm{C}$, would result in an estimated $25 \%$ reduction in flathead sole CPUE. The value of the method described here is in its potential for utilization by managers to make testable predictions about the distribution of flathead sole under varying environmental conditions. Models such as these should prove useful by allowing decision-makers to manage marine ecosystem components, and provide a framework for evaluating options in managing fish habitats.

Acknowledgements. We thank D. Gunderson, J. Ianelli, B. McConnaughey, D. Somerton, J. Boldt and G. Stauffer and 3 anonymous reviewers for providing helpful input on the analyses and manuscript. Additional thanks to G. Walters, NMFS biologists and charter vessel personnel who collected the data analyzed in this manuscript.

\section{LITERATURE CITED}

Abookire AA, Norcross BL (1998) Depth and substrate as determinants of distribution of juvenile flathead sole (Hippoglossoides elassodon) and rock sole (Pleuronectes bilineatus), in Kachemak Bay, Alaska. J Sea Res 39:113-123

Abookire AA, Piatt JF, Norcross BL (2001) Juvenile groundfish habitat in Kachemak Bay, Alaska, during late summer. Alsk Fish Res Bull 8:45-56

Acuna E, Goddard P, Kotwicki S (2003) 2002 bottom trawl survey of the eastern Bering Sea continental shelf. AFSC Processed Rep. 2003-01, Alaska Fisheries Science Center, National Marine Fisheries Service, NOAA, Seattle, WA

Akaike $H$ (1992) Information theory and an extension of the maximum likelihood principle, In: Kotz S, Johnson N (eds) Breakthroughs in statistics, Vol 1. Springer-Verlag, New York, p 610-624

Alderdice DF, Forrester CR (1974) Early development and distribution of the flathead sole (Hippoglossoides elassodon). J Fish Res Board Can 31:1899-1918

Beutel TS, Beeton RJS Baxter GS (1999) Building better wildlife-habitat models. Ecography 22:219-223

Fernandez M, Iribarne O, Armstrong D (1993) Habitat selection by young-of-the-year Dungeness crab Cancer magister and predation risk in intertidal habitats. Mar Ecol Prog Ser 92:171-177

Field ME, Nelson CH, Cacchione DA, Drake DE (1981) Sand waves on an epicontinental shelf: northern Bering Sea. Mar Geol 42:233-258

Freese JL (2001) Trawl-induced damage to sponges observed from a research submersible. Mar Fish Rev 63:7-13

Friedlander AM, Parrish JD (1998) Habitat characteristics affecting fish assemblages on a Hawaiian coral reef. J Exp Mar Biol Ecol 224:1-30

Grigorev SS, Fadeev NS (1995) Distribution of Alaska plaice, flathead sole, and Bering flounder eggs in the Eastern Bering Sea during April-July, 1988-1990. In: Proceedings of International Symposium on North Pacific Flatfish. Alaska Sea Grant College Program Rep No. AK-SG-95-04, University of Alaska, Fairbanks, AK, p 89-100

Haldorson L, Pritchett M, Sterritt D, Watts J (1993) Abundance 
patterns of marine fish larvae during spring in a southeastern Alaskan bay. Fish Bull 91:36-44

Hilborn R, Mangel M (1997) The ecological detective: confronting models with data. Princeton University Press, Princeton, NJ

Holladay BA, Norcross BL (1995) Diet diversity as a mechanism for partitioning nursery grounds of pleuronectids. In: Proceedings of International Symposium on North Pacific Flatfish. Alaska Sea Grant College Program Rep No. AK-SG-9504, University of Alaska, Fairbanks, AK, p 177-203

Howell PT, Molnar DR, Harris, RB (1999) Juvenile winter flounder distribution by habitat type. Estuaries 22:1090-1095

Hunter RE, Thor DR, Swisher ML (1982) Depositional and erosional features of the inner shelf, northeastern Bering Sea. Geol Mijnb 61:49-62

Hutchinson GE (1957) Concluding remarks. Cold Spring Harbor Symp Quant Biol 22:415-427

Iles TC, Beverton RJH (2000) The concentration hypothesis: the statistical evidence. ICES J Mar Sci 57:216-227

Isaaks EH, Srivastava RH (1989) Applied geostatistics. Oxford University Press, Oxford

Kramer DH, Barss WH, Paust BC, Bracken BE (1995) Guide to Northeast Pacific flatfishes: families Bothidae, Cynoglossidae, and Pleuronectidae. Mar Advis Bull 47

Laurel BJ, Gregory RS, Brown JA (2003) Predator distribution and habitat patch area determine predation rates on age- 0 juvenile cod Gadus spp. Mar Ecol Prog Ser 251:245-254

MacCall AD (1990) Dynamic geography of marine fish populations. University of Washington, Press, Seattle, WA

Marlow MS, Stevenson AJ, Chezar H, McConnaughey RA (1999) Tidally generated sea-floor lineations in Bristol Bay, Alaska, USA. Geo-Mar Lett 19:219-226

May RM (1973) Stability and complexity in model ecosystems. Princeton University Press, Princeton, NJ

McConnaughey RA (1995) Changes in geographic dispersion of eastern Bering Sea flatfish associated with changes in population size. In: Proceedings of International Symposium on North Pacific Flatfish. Alaska Sea Grant College Program Rep No. AK-SG-95-04, University of Alaska, Fairbanks, AK, p 385-405

McConnaughey RA, Smith KR (2000) Associations between flatfish abundance and surficial sediments in the eastern Bering Sea. Can J Fish Aquat Sci 57:2410-2419

McConnaughey RA, Mier KL, Dew CB (2000) An examination of chronic trawling effects on soft-bottom benthos of the eastern Bering Sea. ICES J Mar Sci 57:1377-1388

Mineva TA (1964) On the biology of some flatfishes in the eastern Bering Sea. In: Moiseev PA (ed) Soviet fisheries investigations in the northeast Pacific, Pt II, Translation, 1968: Israel Program for Scientific Translations, Jerusalem. US Dep Commerce, Clearinghouse for Fed Sci and Tech Info, Springfield, VA, p 227-235

Murawski SA, Finn JT (1988) Biological basis for mixed-species fisheries: species co-distribution in relation to environmental and biotic variables. Can J Fish Aquat Sci 45:1720-1735

Nichol DG (1998) Annual and between-sex variability of yellowfin sole, Pleuronectes asper, spring-summer distributions in the eastern Bering Sea. Fish Bull 96:547-561

Niebauer HJ, Alexander V, Cooney RT (1981) Primary production at the eastern Bering Sea ice edge: the physical and biological regimes. In: Hood DW, Calder JA (eds) The Eastern Bering Sea Shelf: oceanography and resources, Vol 2. University of Washington Press, Seattle, WA, p 763-772

Norcross BL, Muter FJ, Holladay BA (1997) Habitat models for juvenile pleuronectids around Kodiak Island, Alaska. Fish Bull 95:504-520

Norcross BL, Blanchard A, Holladay BA (1999) Comparison of models for defining nearshore flatfish nursery areas in
Alaskan waters. Fish Oceanogr 8:50-67

North Pacific Management Council (2003) Stock assessment and fishery evaluation report for the groundfish resources of the Bering Sea/Aleutian Islands region, November 2003. North Pacific Fishery Management, Anchorage, AK

O'Brien L, Rago P (1996) An application of the generalized additive model to groundfish survey data with Atlantic cod off the northeast coast of the United States as an example. Northwest Atl Fish Organ Sci Counc Stud 28:79-95

Orth RJ, Heck KL Jr ,Van Montfrans J (1984) Faunal communities in seagrass beds: a review of the influence of plant structure and prey characteristics on predator-prey relationships. Estuaries 7:339-350

Pacunski RE, Livingston PA, Miller BS (1998) Food of flathead sole Hippoglossoides elassodon in the Eastern Bering Sea. NOAA Tech Memo NMFS AFSC-90:

Paul AJ, Paul JM, Smith RL (1995) Energy requirements of fasting flathead sole (Hippoglossoides elassodon Jordan and Gilbert 1880) calculated from respiratory energy needs. In: Proceedings of International Symposium on North Pacific Flatfish. Alaska Sea Grant College Program Rep No. AK-SG-95-04, University of Alaska, Fairbanks, AK, p 297-304

Schumacher JD, Kinder TH (1983) Low-frequency current regimes over the Bering Sea shelf. J Phys Oceanogr 13: $607-623$

Schwab WC, Molnia BF (1987) Unusual bed forms on the north Aleutian shelf, Bristol Bay, Alaska. Geo-Mar Lett 7:207-215

Simpson MR, Walsh SJ (2004) Changes in the spatial structure of Grand Bank yellowtail flounder: testing MacCall's basin hypothesis. J Sea Res 51:199-210

Smith KR, McConnaughey RA (1999) Surficial sediments of the eastern Bering Sea continental shelf: EBSSED database documentation. NOAA Tech Memo NMFS AFSC-104:

Stark JW (2004) A comparison of the maturation and growth of female flathead sole in the central Gulf of Alaska and south-eastern Bering Sea. J Fish Biol 64:1-14

Stevens BG, Anderson PJ (2000) An association between the anemone, Cribrinopsis fernaldi, and shrimps of the families Hippolytidae and Pandalidae. J Northwest Atl Fish Sci 27:77-82

Stoner AW, Titgen RH (2003) Biological structures and bottom type influence habitat choices made by Alaska flatfishes. J Exp Mar Biol Ecol 292:43-59

Stoner AW, Manderson JP, Pessutti JP (2001) Spatially explicit analysis of estuarine habitat for juvenile winter flounder: combining generalized additive models and geographic information systems. Mar Ecol Prog Ser 213:253-271

Swartzman G, Huang C, Kaluzny S (1992) Spatial analysis of Bering Sea groundfish survey data using generalized additive models. Can J Fish Aquat Sci 49:1366-1378

Walsh SJ, Simpson M, Morgan MJ (2004) Continental shelf nurseries and recruitment variability in American plaice and yellowtail flounder on the Grand Bank: insights into stock resiliency. J Sea Res 51:271-286

Wassenberg TJ, Dews G, Cook SD (2002) The impact of fish trawls on megabenthos (sponges) on the north-west shelf of Australia. Fish Res 58:141-151

Wentworth CK (1922) A scale of grade and class terms for clastic sediments. J Geol 30:377-392

Wyllie-Echeverria T, Ohtani K (1999) Seasonal ice variability and the Bering Sea ecosystem. In: Loughlin TR, Ohtani K (eds) Dynamics of the Bering Sea. Alaska Sea Grant College Program Rep No. AK-SG-99-03, University of Alaska, Fairbanks, AK, p 435-451

Zimmermann M, Goddard P (1996) Biology and distribution of arrowtooth, Atheresthes stomias, and Kamchatka, A. evermanni, flounders in Alaskan waters. Fish Bull 94:358-370 